\section{Cerebrospinal Fluid Findings in an Adult with Human Metapneumovirus- Associated Encephalitis}

\author{
Natalie Jeannet, Bernadette G. van den Hoogen, \\ Joerg C. Schefold, Franziska Suter-Riniker, \\ Rami Sommerstein
}

Author affiliations: University of Bern, Bern, Switzerland (N. Jeannet, J.C. Schefold, F. Suter-Riniker, R. Sommerstein); Erasmus Medical Center, Rotterdam, the Netherlands (B.G. van den Hoogen); Bern University Hospital, Bern (J.C. Schefold, R. Sommerstein)

DOI: http://dx.doi.org/10.3201/eid2302.161337

To the Editor: Acute encephalitis/encephalopathy associated with human metapneumovirus (HMPV) has been documented in children (1-3). Recently, Fok et al. (4) described an encephalitis case in an adult but were unable to test cerebrospinal fluid (CSF) for HMPV. Following authors' recommendations, we performed diagnostic testing on the CSF of an adult with HMPV-associated encephalitis.

A previously healthy 61-year-old man came to our institution with headache and seizures 5 days after onset of an influenza-like illness. A lumbar puncture on admission revealed pleocytosis ( 36 cells $/ \mu \mathrm{L})$ and a mononuclear predominance of $98 \%$. Results of magnetic resonance imaging and computed tomography of the head and chest radiography on admission were inconclusive. The patient was treated in the intensive care unit for possible viral and bacterial meningoencephalitis. Although results of routine CSF-workup for infectious causes were unremarkable, total CSF protein level was elevated at $1.39 \mathrm{~g} / \mathrm{L}$ (reference range $0.2-0.4 \mathrm{~g} / \mathrm{L}$ ). A nasopharyngeal swab specimen was positive for HMPV (cycle threshold 28.6) using duplex reverse transcription PCR (r-gene; Biomérieux, Marcy l'Etoile, France).

However, HMPV reverse transcription PCR results were negative in the concurrent CSF sample. Immunofluorescence assays demonstrated HMPV IgG (serum titer 1:8,192; CSF titers 1:64 and 1:32). Indices calculated using the formula ( $\left.\operatorname{IgG}_{\text {CSF }} \mathrm{HMPV} / \mathrm{IgG}_{\text {Serum }} \mathrm{HMPV}\right) /\left(\mathrm{IgG}_{\mathrm{CSF}}\right.$ total//gG $\mathrm{Igerum}_{\text {Sotal }}$ were lower than the cut-off value of 4 , indicating absence of intrathecal IgG against HMPV (Table).

As in the study by Fok et al. (4), our case supports consideration of HMPV as a causative agent of acute encephalitis after respiratory tract infection in adults. We could not demonstrate direct or indirect evidence of HMPV CSF invasion as the cause for HMPV-associated encephalitis in an adult, in contrast to a case in a child in which detection of HMPV in CSF suggested a causative role in acute encephalitis (1). Our data may point toward the role of nonspecific inflammatory response as the main pathogenic factor in HMPV-related encephalitis in adults.

\section{Acknowledgments}

We thank the patient for giving his permission to publish his clinical data.

\section{References}

1. Sánchez Fernández I, Rebollo Polo M, Muñoz-Almagro C, Monfort Carretero L, Fernández Ureña S, Rueda Muñoz A. Human metapneumovirus in the cerebrospinal fluid of a patient with acute encephalitis. Arch Neurol. 2012;69:649-52. http://dx.doi.org/10.1001/archneurol.2011.1094

2. Vehapoglu A, Turel O, Uygur Sahin T, Kutlu NO, Iscan A. Clinical significance of human metapneumovirus in refractory status epilepticus and encephalitis: case report and review of the literature. Case Rep Neurol Med. 2015;2015:131780. http://dx.doi.org/10.1155/2015/131780

3. Niizuma T, Okumura A, Kinoshita K, Shimizu T. Acute encephalopathy associated with human metapneumovirus infection. Jpn J Infect Dis. 2014;67:213-5. http://dx.doi.org/ 10.7883/yoken.67.213

4. Fok A, Mateevici C, Lin B, Chandra RV, Chong VH. Encephalitis-associated human metapneumovirus pneumonia in adult, Australia. Emerg Infect Dis. 2015;21:2074-6. http://dx.doi.org/10.3201/eid2111.150608

Address for correspondence: Rami Sommerstein, Department of Infectious Diseases, Inselspital, Bern University Hospital, Freiburgstrasse 18 CH 3010 Bern, Switzerland; email: rami.sommerstein@insel.ch

\begin{tabular}{|c|c|c|c|}
\hline \multirow[b]{2}{*}{ Test } & \multicolumn{2}{|c|}{ Sample type, result or IgG titer } & \multirow[b]{2}{*}{ HMPV IgG index } \\
\hline & Nasopharyngeal swab & CSF & \\
\hline Reverse transcription PCR & Positive (cycle threshold 28.6) & Negative & \\
\hline \multicolumn{4}{|l|}{ Immunofluorescence assays } \\
\hline Vero- 118 cells infected with HMPV NL/1/00 & $1: 8,192$ & 1:32 & 0.54 \\
\hline Vero-118 cells infected with HMPV NL/1/99 & $1: 8,192$ & $1: 64$ & 1.07 \\
\hline
\end{tabular}

